Lilly, MSD, Pfizer, Roche, Sanofi Aventis, UCB, Anja Strangfeld Speakers bureau: AbbVie, BMS, Pfizer, Roche, Sanofi-Aventis DOI: 10.1136/annrheumdis-2020-eular.1210

\section{SAT0438 $\quad$ REAL-WORLD TREATMENT PERSISTENCE WITH BIOLOGIC DISEASE MODIFYING ANTIRHEUMATIC DRUGS AMONG GERMAN PATIENTS WITH PSORIATIC ARTHRITIS}

P. Sewerin ${ }^{1}$, K. Borchert ${ }^{2}$, D. Meise ${ }^{2}$, J. Mahlich ${ }^{3,4} .{ }^{1}$ Heinrich-Heine University, Department for Rheumatology, Duesseldorf, Germany; ${ }^{2}$ Xcenda $\mathrm{GmbH}$, Hannover, Germany; ${ }^{3}$ Janssen-Cilag GmbH, Neuss, Germany; ${ }^{4}$ HeinrichHeine University, Duesseldorf Institute for Competition Economics (DICE), Duesseldorf, Germany

Background: Persistence rates of biologic disease modifying antirheumatic drugs (bDMARDs), which refer to the duration of time from initiation to discontinuation or switch of therapy, have been shown to vary considerably depending on the country, types of health centers, as well as the specific drug being investigated. Evidence on treatment persistence of psoriatic arthritis (PsA) patients in Germany is scarce.

Objectives: Our aim was to study drug survival of bDMARDs in a German realworld cohort of adult biologic-naïve psoriatic arthritis patients.

Methods: We utilized the German "Institut für angewandte Gesundheitsforschung Berlin" (InGef) research database consisting of about 4 million covered lives structured to represent the German population in terms of age and gender according to the Federal Office of Statistics (DESTATIS). Thereof, 2.9 million patients were continuously enrolled in the study period spanning from January $1^{\text {st }}, 2013$ and December $31^{\text {st }}, 2018$. For the analysis of persistence rates, the study population was identified based on the International Classification of Diseases, German Modification (ICD-10-GM) and claims records of biologic prescriptions based on ATC codes. Adult patients who had a diagnosis of psoriasis arthritis (L40.5 in combination with M07.0 or M07.1 or M07.2 or M07.3) in the inpatient or outpatient setting, and a claims record of biologic treatment licensed for psoriasis arthritis between January $1^{\text {st }}, 2014$ to December $31^{\text {st }}, 2017$ were included. Patients with Crohn's disease (K50), ulcerative colitis (K51), ankylosing spondylitis (M45), and rheumatoid arthritis (M05-M07) were excluded. Biologic-naïve patients were identified as those who had no prior record of bDMARDs prescription during the 12 months before the index date ('washout'). The index date was defined as the first claim for a biologic agent. Non-persistence occurred if a treatment gap exceeding the days of supply plus 60 days or a switch to a bDMARD other than the index therapy was observed. Days of supply were calculated based on the daily defined doses defined by the WHO for the respective bDMARDs. Kaplan-Meier curves were plotted to show the persistence of different biologics. The log-rank test was used to test for differences in the 1-year persistence rate.

Results: Among 10,954 patients with a diagnosis of PsA, 348 biologic-naïve patients aged 18 years or above were identified. The one-year overall persistence rate was $57.5 \%$ for all bDMARD compounds. Reasons for non-persistence were switches to a different bDMARD agent in $15.8 \%$ of patients and $26.7 \%$ discontinued treatment. The highest persistence rate was observed for ustekinumab (81.3\%), which was significantly higher than the respective rates for adalimumab $(58.1 \%)$, certolizumab pegol (51.7\%), etanercept $(51.0 \%)$, or secukinumab $(54.7 \%)$.

Conclusion: Persistent rates for a real-world cohort of German PsA patients are modest with significant variations among different bDMARD therapies.

Disclosure of Interests: Philipp Sewerin Grant/research support from: AbbVie Deutschland $\mathrm{GmbH} \& \mathrm{Co}$. KG

Bristol-Myers Squibb Celgene $\mathrm{GmbH}$

Lilly Deutschland $\mathrm{GmbH}$

Novartis Pharma GmbH Pfizer Deutschland $\mathrm{GmbH}$

Rheumazentrum Rhein-Ruhr, Consultant of:AMGEN GmbH AbbVie Deutschland $\mathrm{GmbH} \&$ Co. KG Biogen GmbHBristol-Myers Squibb Celgene GmbH Chugai Pharma arketing Ltd. / Chugai Europe GmbHHexal Pharma Janssen-CilagGmbH Johnson \& Johnson Deutschland GmbHLilly Deutschland GmbH / Lilly Europe / Lilly Global Novartis Pharma GmbH Pfizer Deutschland GmbH Roche Pharma Rheumazentrum Rhein-Ruhr Sanofi-Genzyme Deutschland GmbH Swedish Orphan Biovitrum GmbH UCB Pharma GmbH, Speakers bureau: AMGEN GmbH AbbVie Deutschland GmbH \& Co. KG Biogen GmbHBristol-Myers Squibb Celgene GmbH Chugai Pharma arketing Ltd. / Chugai Europe GmbHHexal Pharma Janssen-CilagGmbH Johnson \& Johnson Deutschland GmbHLilly Deutschland GmbH / Lilly Europe / Lilly Global Novartis Pharma GmbH Pfizer Deutschland GmbH Roche Pharma Rheumazentrum Rhein-Ruhr Sanofi-Genzyme Deutschland GmbH Swedish Orphan Biovitrum GmbH UCB Pharma GmbH, Kathrin Borchert Consultant of: Janssen-Cilag GmbH, Dominic Meise Consultant of: Janssen-Cilag GmbH, Jörg Mahlich Shareholder of: Janssen-Cilag $\mathrm{GmbH}$, Employee of: Janssen-Cilag $\mathrm{GmbH}$

DOI: 10.1136/annrheumdis-2020-eular.6382

\section{SAT0439 POWER DOPPLER ULTRASOUND ASSESSMENT OF A1 PULLEY. A NEW TARGET IN PSORIATIC ARTHRITIS?}

G. Smerilli ${ }^{1}$, E. Cipolletta ${ }^{1}$, M. DI Carlo ${ }^{1}$, A. DI Matteo ${ }^{1}$, W. Grassi ${ }^{1}$,

E. Filippucci ${ }^{1} .{ }^{1}$ Polytechnic University of Marche, Rheumatology Unit, Department of Clinical and Molecular Sciences, "Carlo Urbani" Hospital, Jesi, Italy

Background: In the last few years annular pulleys inflammation has been highlighted as a possible key pathogenetic factor in psoriatic dactylitis, first with magnetic resonance imaging (MRI) ${ }^{1}$, then, in a very recent paper $^{2}$, with power Doppler (PD) ultrasound (US). However, the prevalence of PD US inflammation of annular pulleys in psoriatic arthritis ( $P s A$ ) patients compared to rheumatoid arthritis (RA) patients has not been investigated yet.

Objectives: To determine the prevalence of PD US findings indicative of A1 pulley inflammation in PsA patients and in controls with RA and to preliminarily investigate the correlation between A1 pulley inflammation and disease activity (DAPSA) Methods: Consecutive patients with PsA and RA were included in this cross-sectional single-centre study. A rheumatologist recorded demographic and clinica data and in the same day another rheumatologist performed the US examination using a MyLab ClassC (Esaote, Genova, Italy) equipped with a 10-22 $\mathrm{MHz}$ linear probe. A1 pulleys of fingers $2^{\text {nd }}$ to $5^{\text {th }}$ were assessed bilaterally adopting longitudinal and transverse scans. The following pathological US findings were recorded: inflammation of the pulley (defined as the presence of PD signal within a thickened pulley) and tenosynovitis of the digital flexor tendons at finger level according to OMERACT definition.

Results: Sixty patients were enrolled: 30 with PsA and 30 with RA. Inflammation of $A 1$ pulley was found in 15 out 240 fingers (6.3\%) of $8(26.7 \%)$ PsA patients and in 1 out of 240 fingers $(0.4 \%)$ of $1(3.3 \%)$ RA patients $(p<0.01$ and $p=0.03$ respectively). Both pulley inflammation and tenosynovitis were correlated with DAPSA ( $R p b=0.56, p<0.01$ and $R p b=0.48, p<0.01$ ). In fact, 7 out 8 (88\%) PsA patients with at least one inflamed A1 pulley had a moderate/high disease activity score. The regression linear analysis $(R 2=0.36$, adjusted $R 2=0.31)$ showed that $A 1$ pulley inflammation was correlated with higher DAPSA scores $(\beta=0.43$, $p=0.03$ ). No significant association was reported between $A 1$ pulley inflammation and past or current episodes of dactylitis $(p=0.09)$. However, the only current dactylitis assessed showed A1 pulley inflammation.

Conclusion: This pilot study demonstrated that ultrasound A1 pulley inflammation, defined as the presence of power Doppler signal within a thickened pulley, is relatively common at patient level in psoriatic arthritis and seems to be characteristic of PsA compared to RA. In psoriatic arthritis patients, a positive significant correlation was found between ultrasound $A 1$ pulley inflammation and disease activity References:

[1] Tan AL, Fukuba E, Halliday NA, Tanner SF, Emery P, McGonagle D. High-resolution MRI assessment of dactylitis in psoriatic arthritis shows flexor tendon pulley and sheath-related enthesitis. Ann Rheum Dis 2015; 74: 185-9.

[2] Tinazzi I, McGonagle D, Macchioni P, Aydin SZ. Power Doppler enhancement of accessory pulleys confirming disease localization in psoriatic dactylitis. Rheumatology (Oxford) 2019 [Epub ahead of print].

Disclosure of Interests: Gianluca Smerilli: None declared, Edoardo Cipolletta: None declared, Marco Di Carlo: None declared, Andrea Di Matteo Grant/research support from: the publication was conducted while Dr. Di Matteo was an ARTICULUM fellow, Walter Grassi Speakers bureau: Prof. Grassi reports personal fees from AbbVie, personal fees from Celgene, personal fees from Grünenthal, personal fees from Pfizer, personal fees from Union Chimique Belge Pharma outside the submitted work., Emilio Filippucci Speakers bureau: Dr. Filippucc reports personal fees from AbbVie, personal fees from Bristol-Myers Squibb, personal fees from Celgene, personal fees from Roche, personal fees from Union Chimique Belge Pharma, personal fees from Pfizer, outside the submitted work. DOI: 10.1136/annrheumdis-2020-eular.1404

\section{SAT0440 METHOTREXATE SURVIVAL RATE IN PATIENTS WITH PSORIATIC ARTHRITIS FROM PSORIATIC ARTHRITIS -INTERNATIONAL DATABASE (PSART-ID) COHORT}

D. Solmaz ${ }^{1}$, U. Kalyoncu ${ }^{2}$, I. Tinazzi ${ }^{3}$, O. Bayindir ${ }^{4}$, E. Dalkılıç ${ }^{5}$, A. Dogru ${ }^{6}$, C. Özişler ${ }^{7}$, G. Kimyon ${ }^{8}$, G. Yildirim Cetin ${ }^{9}$, A. Omma ${ }^{10}$, E. F. Tarhan ${ }^{1}$, L. Kılıç ${ }^{2}$, S. Akar ${ }^{1}$ S. Yıımaz ${ }^{11}$, M. Can ${ }^{12}$, S. Yavuz ${ }^{12}$, O. Küçükşahinn ${ }^{7}$ S. Bakırcı ${ }^{13}$, S. Aydin ${ }^{14}$. ${ }^{1}$ Izmir Katip Celebi University School of Medicine, Izmir, Turkey; ${ }^{2}$ Hacettepe University School of Medicine, Ankara, Turkey; ${ }^{3}$ Ospedale Sacro Cuore, Verona, Italy; ${ }^{4}$ Ege University, Izmir, Turkey; ${ }^{5}$ Uludag University, Bursa, Turkey; ${ }^{6}$ Suleyman Demiral University, Isparta, Turkey; ${ }^{7}$ Dis Kapi Yildirim Beyazit Education and Research Hospital, Ankara, Turkey; ${ }^{8}$ Mustafa Kemal University, Hatay, Turkey; ${ }^{9}$ Kahramanmaraş Sutcu Imam University, Kahramanmaras, Turkey;

${ }^{10}$ Ankara Numune Education and Research Hospital, Ankara, Turkey; ${ }^{11}$ Selcuk University, Konya, Turkey; ${ }^{12}$ Marmara University, Istanbul, Turkey; ${ }^{13}$ Antalya 